\title{
A cenografia de manifesto político na produção discursivo-literária de su- jeitos transgêneros
}

Rafael COSSETTI

\section{Considerações iniciais}

Este capítulo deriva da pesquisa desenvolvida no curso de mestrado do Programa de Pós-Graduação em Linguística da Universidade Federal do Espírito Santo. Examinamos aqui a produção discursivo-literária de sujeitos transgêneros desenvolvida em uma cenografia de manifesto político e a constituição de sua paratopia. A valorização dos discursos produzidos por esses sujeitos requer uma luta contra essencialismos e dicotomias. É necessário problematizar posicionamentos assentados em modelos tradicionais e homogêneos, alicerçados em relações políticas de subordinação 
e de dominação. Torna-se imprescindível refletir sobre mudanças sociais recentes, seja no dia a dia, seja na condução de nossas pesquisas. Somente com esse questionamento, abre-se espaço para uma perspectiva que celebre a complexidade da diferença.

Recorremos às orientações de Jaqueline Gomes de Jesus ${ }^{24}$ (2012) para delimitarmos que se trata de um conceito "guarda-chuva" utilizado para um conjunto diversificado de sujeitos que não se identificam, de formas e em graus diferentes, com comportamentos e/ou papéis esperados do gênero que lhes foi designado antes mesmo do momento do nascimento. Trata-se de um termo para dar conta de sujeitos com vivências bastante distintas que lutam contra a rede complexa de regulação social que organiza e modela identidades, corpos e comportamentos.

Fundamentamo-nos no aporte teórico-metodológico da Análise do Discurso de linha francesa (AD), de modo particular, na perspectiva enunciativo-discursiva desenvolvida por Dominique Maingueneau (2008, 2010, 2016a, 2016b). A fim de darmos conta do caráter interdisciplinar da análise, dialogamos com a perspectiva teórico-política queer, representada, neste trabalho, pelas obras de Judith Butler (2002, 2015, 2016). Nessa orientação, aborda-se o gênero social como um conjunto de atos performativos, ou seja, uma norma que se materializa discursivamente. A pesquisa é de cunho analítico e emprega como corpus três discursos literários da coletânea Nós, trans: escrevivências de resistência do Grupo Transcritas Coletivas $^{25}$.

24 Escolhemos mencionar o nome completo dos autores principais que fundamentam esta pesquisa, quando aparecem pela primeira vez no texto. Com isso, intencionamos identificá-los de forma reverenciosa. A autora Jaqueline Gomes de Jesus é responsável por um dos discursos literários analisados.

25 Referimo-nos aos discursos por meio da referência Grupo Transcritas Coletivas, com o intuito de respeitar a forma coletiva de sua produção, indicando nas notas a responsabilidade de cada discurso. 
Segundo Maingueneau (2016a), a paratopia é o caráter paradoxal dos discursos constituintes, como os discursos religioso, filosófico, científico e literário, os quais se comportam como discursos fundadores que validam a si próprios por meio de suas cenas de enunciação. A paratopia articula-se em um investimento de uma cenografia que faz do discurso um lugar de representação de sua própria enunciação, de um ethos discursivo que faz emergir do discurso uma voz que ativa o imaginário estereotípico de um corpo enunciante socialmente avaliado e de um código linguageiro, cuja configuração específica opera sobre a diversidade de zonas e registros de língua com um efeito prescritivo que liga o ato de enunciação que dá origem ao discurso ao universo de sentido que ele realça.

Justificamos esse estudo devido à importância da inserção da Linguística na compreensão do discurso literário e à valorização de discursos produzidos por sujeitos que historicamente foram e continuam sendo marginalizados, inclusive, pelos discursos científico-acadêmicos. $\mathrm{O}$ caráter interdisciplinar da $\mathrm{AD}$ viabiliza a pesquisa sobre o resgate e a criação, por meio do discurso literário, de uma memória coletiva na conjuntura atual de produção e de circulação desse tipo de discurso.

O capítulo está organizado em três seções. Na primeira, discutimos a investida dos discursos literários produzidos por sujeitos trans contra uma conjuntura sociocultural de pelo menos três séculos que os exclui de diversas maneiras. Na segunda, tratamos das especificidades do discurso literário e analisamos o corpus, empregando as categorias sobre as quais incide a paratopia. Na terceira, retomamos os resultados da análise e indicamos caminhos para a ampliação desse estudo. 


\section{Das narrativas sobre os sujeitos transgêneros ao discurso literário como contradiscurso}

$\mathrm{Na}$ perspectiva teórico-política queer, o controle sobre os corpos e identidades de gênero é reconhecido como um dispositivo de poder e saber. Os sujeitos trans ${ }^{26}$ acabam não sendo vistos como seres humanos, mas como seres abjetos "cujas vidas não são consideradas 'vidas' e cuja materialidade é entendida como 'não importante"' (BUTLER, 2002, p. 161), ou seja, por não serem inteligíveis dentro dos padrões hegemônicos de gênero e de sexualidade baseados em um sistema binário.

Esses padrões são rejeitados quando se percebe o gênero, como o faz Butler $(2002,2016)$, como um conjunto de atos performativos, visão que permite compreender as vivências trans fora dos modelos patológicos. Apropriar-se de termos ofensivos, assim, mostra-se como uma maneira de subversão, uma prática que rivaliza com os valores que tornam esses enunciados depreciativos possíveis. Para além da aceitação de um lugar "minoritário", a perspectiva teórico-política queer ${ }^{27}$ propõe uma genealogia dos discursos que instituem a heterossexualidade como norma compulsória.

Dentro dessa visão queer, assumimos "contradiscurso" como uma posição de resistência e subversão da matriz cisgênera e heterossexual. Os discursos literários constituídos em um regime de escrita de si buscam responder a uma conjuntura sociocultural de

26 O termo "trans" será empregado para se referir a "transgênero".

27 Para Larissa Pelúcio (2014), devemos refletir sobre a forma segundo a qual adaptamos a perspectiva teórico-política queer ao contexto brasileiro. As categorias de gênero, de sexualidade e de raça/etnia se sobrepõem de forma distinta no contexto brasileiro daquele referenciado pelas/os autoras/es estrangeiras/os pertencentes a essa corrente. Essas/es pensadoras/es adotaram a ofensa "queer", uma identidade apontada mas até então não reivindicada, e conformaram um lugar político. Ademais, como o termo "queer" não significa nada ao senso comum brasileiro, perde-se a politização do termo desqualificador. 
três séculos ${ }^{28}$ que exclui sujeitos que não se conformam a suas regras compulsórias. Somente uma teoria e uma política pós-identitárias conseguem promover uma crítica a essa conjuntura sem se acabarem presas por sua lógica de prescrição de identidades a serem seguidas.

Os discursos literários que tematizam o próprio sujeito responsável por eles, as escritas de si, respondem a uma cena de interpelação que pergunta “quem é você?". Segundo Butler (2015), um sujeito tematiza a si próprio em um discurso quando é obrigado por um sistema de justiça e castigo. No caso dos discursos que compõem nosso corpus, a consideração desses sujeitos como seres abjetos incita que essa cena se configure violentamente. Mesmo assim, os enunciadores respondem e o fazem de modo a possibilitar uma discussão sobre direitos.

\section{O discurso literário como discurso constituinte}

O discurso literário participa, como defende Maingueneau (2016a), junto com os discursos religioso, científico e filosófico, de um plano determinado da produção verbal, o dos discursos constituintes. Por terem acesso privilegiado a uma fonte extrassocial, uma Origem, esses discursos localizam-se na fronteira entre o mundo comum e um mundo superior, que excede o mundo humano. Essa característica faz com que eles sejam validados por uma cena de enunciação que os autoriza. À primeira vista, esses discursos parecem muito distintos, porém é possível agrupá-los em uma mesma categoria devido à sua "[...] função (fundar e não ser fundado por outro discurso), [a] certo recorte das situações de 28 Produzimos na nossa dissertação de mestrado um capítulo dedicado à discussão das condições sócio-históricas de produção das narrativas sobre os sujeitos trans. Ver Cossetti (2019). 
comunicação de uma sociedade (há lugares e gêneros vinculados a esses discursos constituintes) e [a] certo número de invariantes enunciativas" (MAINGUENEAU, 2016a, p. 61).

A fim de caracterizar a posição privilegiada desses discursos, Maingueneau (2016a) recorre à noção de archeion de uma coletividade.

Esse termo grego, étimo do termo latino archivum, apresenta uma interessante polissemia para a nossa perspectiva: ligado a arché, "fonte", "princípio", e, a partir disso, "mandamento", "poder", o archeion é a sede da autoridade, de um palácio, por exemplo, um corpo de magistrados, mas igualmente os arquivos públicos. Ele associa, dessa maneira, intimamente, o trabalho de fundação no e pelo discurso, a determinação de um lugar vinculado com um corpo de locutores consagrados e uma elaboração da memória. Os discursos constituintes são discursos que conferem sentido aos atos da coletividade [...] (MAINGUENEAU, 2016a, p. 61).

Por estarem vinculados ao archeion, os discursos constituintes dão significado aos atos da coletividade e servem de fonte para os outros tipos de discurso. Isto é, esse estatuto único torna-os a um só tempo autoconstituintes e heteroconstituintes: somente um discurso que se constitui gerindo em termos textual-discursivos sua própria emergência pode servir de fonte para outros discursos.

Maingueneau (2016a) aponta que, nesse modo de constituição, há duas dimensões indissociáveis. Sua constituição se refere tanto a uma ação de se estabelecer legalmente, regrando sua emergência no interdiscurso, quanto aos modos de organização, em um sen- 
tido de estruturação de elementos que compõem uma totalidade textual. Nessa perspectiva, uma análise da "constituência" ${ }^{29}$ desse tipo de discurso

[...] deve concentrar-se em mostrar o vínculo inextricável entre o intradiscursivo e o extradiscursivo, a imbricação entre uma organização textual e uma atividade enunciativa. Sua enunciação se instaura como dispositivo de legitimação de seu próprio espaço, incluindo seu aspecto institucional; ela articula o engendramento de um texto e uma maneira de inscrever-se num universo social (MAINGUENEAU, 2016a, p. 62).

A inscrição dos discursos constituintes no universo social leva o autor a tratar da produção, do consumo e das relações que esses discursos mantêm com as mais diversas instituições sociais. Sem se filiarem a elas por completo, esses discursos guardam uma condição paradoxal. Isto é, o discurso literário, enquanto discurso constituinte, apesar de surgir em diferentes âmbitos sociais, não se fixa em nenhum deles; conserva-se em um pertencimento impossível.

Esse pertencimento paradoxal alimenta o próprio ato de enunciação, que acaba se revestindo da impossibilidade de inscrição tanto no interior quanto no exterior da sociedade. Quem produz um discurso constituinte "[...] não pode situar-se no exterior nem no interior da sociedade: está fadado a dotar sua obra do caráter radicalmente problemático de seu próprio pertencimento a essa sociedade" (MAINGUENEAU, 2016a, p. 68). Resta uma difícil negociação entre lugar e não lugar. Esse caráter paradoxal, que se manifesta discursivamente, é denominado paratopia.

29 O termo "constituência" é específico da $\mathrm{AD}$, especialmente vinculado a diversos textos de Dominique Maingueneau que tratam de discursos constituintes. Serve para enfatizar o caráter de autoinstauração desses discursos. 
Em seus primeiros trabalhos sobre o discurso literário, Maingueneau (1995) cunha a noção de embreagem paratópica, um conjunto de relações que participam simultaneamente do potencial paratópico dos produtores desses discursos e do mundo delineado por eles. Podemos analisá-la em termos de categorias, como a cenografia, o ethos discursivo e o código linguageiro. Tratamos de cada uma dessas categorias para procedermos à análise do corpus na próxima seção.

A cenografia é instituída no e pelo próprio discurso, e é com ela que o interlocutor, enredado em uma determinada enunciação, lida diretamente. A cenografia legitima e é legitimada pelo discurso, confundindo-se com o enunciado que sustenta, e o enunciado, por sua vez, também sustenta a cenografia. No entanto, a cenografia não se trata de um simples suporte; ela é, antes, um dispositivo capaz de articular a obra e as condições que propiciam sua criação. Maingueneau (1997) esclarece esse dispositivo, constituído por elementos da dêixis discursiva ${ }^{30}$, a partir de coordenadas espaçotemporais implicadas na cena de enunciação, que consistem em um primeiro acesso à cenografia; ela implica uma figura de enunciador e co-enunciador, uma cronografia (um momento) e uma topografia (um lugar), marcas das quais o discurso pretende emergir. Se existe dêixis discursiva é porque a formação discursiva não enuncia a partir de um sujeito, de uma conjuntura histórica e de um espaço evidentemente determináveis, mas a partir da cena que sua enunciação produz. A escolha da cenografia é essencial para constituir e legitimar seu ethos discursivo e para mostrar que o enunciador negociou um código linguageiro adequado àquele universo.

30 A dêixis e a dêixis discursiva possuem a mesma função, mas esta se manifesta "num nível diferente: o do universo de sentido que uma formação discursiva constrói através de sua enunciação. Em geral, as três instâncias da dêixis discursiva não correspondem a um número idêntico de designação nos textos, mas cada uma recobre uma família de expressões em relação de substituição. Distinguir-se-á nesta dêixis o locutor e o destinatário discursivos, a cronografia e a topografia" (MAINGUENEAU, 1997, p. 41). 
O ethos discursivo é construído por meio do discurso em um processo interativo de influência sobre o co-enunciador. Isto é, concerne um comportamento socialmente avaliado, que é compreendido dentro de uma situação específica de comunicação e de uma conjuntura sócio-histórica determinada. Além disso,

[...] o ethos implica uma maneira de se mover no espaço social, uma disciplina tácita do corpo apreendida através de um comportamento. O destinatário a identifica apoiando-se num conjunto difuso de representações sociais avaliadas positiva ou negativamente, em estereótipos que a enunciação contribui para confrontar ou transformar: o velho sábio, o jovem executivo dinâmico, a mocinha romântica... (MAINGUENEAU, 2008, p. 18).

A ideia de que cada discurso possui um tom específico que aponta para seu enunciador implica também a determinação de uma instância subjetiva encarnada que desempenha a função de fiador. Por meio de indícios textuais, o co-enunciador constrói um conjunto de traços físicos e psíquicos que se sustentam em representações sociais valorizadas ou desvalorizadas, em estereótipos culturais, que são reforçados ou transformados (MAINGUENEAU, 2016a).

Já o código linguageiro diz respeito a uma configuração específica que determinada formação discursiva emprega no momento da enunciação, posto que ela não enuncia por meio de uma língua, mas através de um código específico (MAINGUENEAU, 2016a). O uso que se faz da língua é constitutivo de uma formação discursiva e este código participa da autolegitimação do enunciador. Em se tratando de campo literário, o criador negocia um código linguageiro que lhe é característico, isto é, realiza a interação da sua produção com outros códigos. 


\section{Diferença e coletividade na cenografia de manifes- to político}

Com base nos apontamentos e nas categorias apresentadas brevemente até aqui, analisamos nesta seção os três discursos literários produzidos por sujeitos trans que compõem o nosso corpus. Os três discursos fazem parte da coletânea Nós, trans: escrevivências de resistência do Grupo Transcritas Coletivas (2017), publicada no formato de livro eletrônico pela LiteraTRANS. Essa editora é voltada exclusivamente à produção discursivo-literária de sujeitos trans e mantém envolvida na parte criativa da produção dos livros somente sujeitos trans. Essa política de valorização garante uma interferência mínima de sujeitos cisgêneros e, por consequência, uma produção discursivo-literária lídima desses sujeitos.

Sem nos limitarmos às marcas linguísticas, observamos o interdiscurso, a cenografia, o ethos discursivo e o código linguageiro, a fim de examinarmos o funcionamento da paratopia. Uma vez que a paratopia se manifesta em dois níveis, o de discurso constituinte e o de cada produtor/a de um discurso constituinte (MAINGUENEAU, 2016a), nossa análise considera a cenografia como produto central do nível do discurso constituinte e o ethos discursivo como projeção da/o produtora/o desses discursos.

Nos três discursos selecionados, temos uma cenografia construída por meio da apresentação da situação de vulnerabilidade na qual se encontram os sujeitos trans e de proposições de mudança. Nesses discursos, os enunciadores apresentam, mesmo que ironicamente, sugestões de ação que almejam reivindicar direitos e respeito às identidades dissidentes, além de encorajá-las a um pertencimento identitário coletivo. 
Predominam, nos discursos selecionados, interdiscursos que tornam possíveis a apresentação de uma conjuntura sócio-histórica de produção de narrativas sobre os sujeitos trans. Trata-se de uma conjuntura sustentada por um olhar heteronormativo e cisgênero sobre esses sujeitos. À primeira vista, temos interdiscursos do campo político. Mesmo que seja conduzida uma cena na qual se apresente um sujeito enunciador particular, a ideia de uma coletividade trans percorre esses discursos.

Reconhecemos a cenografia de manifesto político como uma configuração que se desenrola em duas partes de orientação pragmático-discursiva distinta: uma inicial e maior que efetua uma exposição da situação dos sujeitos trans no contexto sócio-histórico brasileiro, tecendo-lhe uma série de críticas; e outra que apresenta um projeto que reivindica mudança social e respeito a essas identidades. Nessa cenografia, está presente uma busca pela adesão do co-enunciador, muitas vezes, através da insistência de um paralelismo frasal, cujo efeito que se acumula é argumentativo. Também notamos enunciados que solicitam ao co-enunciador uma ação, que acompanhe na necessária transformação social. Para tanto, faZ-se referência a dois tempos, um atual, de não pertencimento, de exclusão e de violência, e um futuro, de possibilidade, de reconhecimento, de respeito. Na sequência, temos o primeiro deles:

(A1) Meu corpo e o não lugar que ocupo ${ }^{31}$

(1) Nosso gênero é pré-definido desde o momento em que estamos na barriga de quem nos pariu, quando, no exame de ultrassom, encontram vestígios de pedaços de corpo que servem para nos enquadrar em um dos signos

31 Discurso assinado por Jef Cardoso Oliveira. No livro, há divergência na indicação do sobrenome. Na página do discurso, aparece Cardoso, enquanto da página da minibiografia consta Oliveira. Optamos, então, por designar ambos. 
binários de identidade: ou se é menino ou se é menina. A partir daí, começa-se a saga de customização do feto, atribuem-nos nome, compram-nos as cores e os enxovais, criam para nós os planos de nossa vida em um momento em que ainda nós não podemos contestar. Assim que nascemos nos registram, com aquele pedaço de corpo já visível burocratizam nosso ser, certificam o nosso gênero/sexo e nome. E até percebermos e contrariarmos o que fora estabelecido, continuarão a deslegitimar nossas afirmações sobre nós mesmos. É nesse momento que começamos a nossa própria saga de desconstrução do sujeito que nos foi estabelecido.

(2) E quando a forma que você se compreende e se identifica não é reconhecida pela sociedade e pelo Estado? E quando a sua identidade é uma grande negação à estrutura cis-hetronormativa e binária de gênero?

(3) Existe uma grande batalha a ser travada contra todo um cis-tema heteronormativo e binário-excludente que cotidianamente violenta corpos destoantes da normatividade. Violenta-nos no sentido de nos empurrar para o lugar da marginalidade social, nos tornar vulneráveis e nos enfraquecer, de uma forma que consiga alcançar o seu objetivo que é de nos eliminar. Pois, esse mesmo cis-tema compreende que nossos corpos são perigosos e ameaçam toda a cadeia de privilégios que eles criaram. E essa violência se torna mais aguda quando o seu corpo é negro. O ser negro e não normativo aumenta o nível de periculosidade em face desse mesmo cis-tema que também é racista. 
(4) O corpo que habito não se conforma e nega todas as estruturas sistemáticas de fácil inteligibilidade. Este corpo não se reconhece enquanto homem, tampouco enquanto mulher. É um corpo que flui, que vivencia experiências próprias de gênero. Um corpo rebelde, desobediente ao comportamento de gênero que outrora lhe foi designado. Um corpo não binário negro que resiste.

(5) Meu corpo também faz ocupações; meu corpo ocupa-se de um não lugar no mundo, um não lugar na sociedade, ocupa os limbos identitários, que servem para caber os corpos esquecidos, os corpos subalternos, corpos abjetos, fora do espectro imaginário do desejo e da afetividade, corpos que estão em constante dissidência à normatividade compulsória, aqueles corpos que não representam nada além deles mesmos. Corpos repletos de autopertencimento e autorrepresentação em que a consequência dessa desconhecida liberdade e autonomia de ser é a constante solidão. Porém, nunca é alto o preço a se pagar pelo privilégio de pertencer a si mesmo.

(GRUPO TRANSCRITAS COLETIVAS, 2017, p. 21-22).

Em relação à cenografia de manifesto político, temos logo em $\left[\mathrm{A} 1 \$ 1^{\circ}\right]$ uma afirmação generalizante sobre o gênero: "Nosso gênero é pré-definido desde o momento em que estamos na barriga de quem nos pariu [...]" (GRUPO TRANSCRITAS COLETIVAS, 2017, p. 21). O caráter prescritivo do gênero cria uma associação necessária entre algumas características físicas e uma identidade de gênero bem delineada. Essa asserção inicial começa a traçar uma cena que ameaça e exclui as identidades trans. 
No final desse mesmo parágrafo, o enunciador faz referência, pela primeira vez, àqueles sujeitos que não se conformam à cisgeneridade por intermédio da criação de uma cena cujo tempo (cronografia) é de reivindicação e de mudança. Salientar que há um momento em que se começa uma "saga de desconstrução do sujeito que nos foi estabelecido" (GRUPO TRANSCRITAS COLETIVAS, 2017, p. 21) amarra a enunciação a um tempo que requer a participação dos sujeitos trans na transformação desse cenário prejudicial.

A argumentação em defesa das identidades trans, iniciada com a asserção generalizante em $\mathrm{A} 1 \$ 1^{\circ}$, continua em A $1 \$ 2^{\circ} \mathrm{com}$ a utilização de perguntas retóricas. Essas perguntas constroem um efeito de maior proximidade com o co-enunciador, dado que se mostram como um convite à sua reflexão sobre exclusão dos sujeitos trans e, assim, evidenciam a necessidade de mudança desse cenário.

Em $\mathrm{A} 1 \$ 3^{\circ}$, a rede argumentativa traça um diagnóstico da situação dos sujeitos trans a começar pela afirmação de que "existe uma grande batalha a ser travada contra todo um cis-tema heteronormativo e binário-excludente" (GRUPO TRANSCRITAS COLETIVAS, 2017, p. 21). Essa cena, a princípio traçada em [A1\$1 $\left.{ }^{\circ}\right]$ com "é nesse momento" e ratificada aqui pela seleção de "existe", marca a necessidade da ação para uma mudança futura. Esse quadro de exclusão e de violência é disposto nesse parágrafo a fim de atestar a urgência da transformação.

Com $\mathrm{A} 1 \$ 4^{\circ}$, dá-se início a uma cena de autoafirmação da posição do sujeito enunciador. Confirma-se aqui outra instância da dêixis discursiva: a cenografia desdobra-se em um lugar (topografia) de ocupação, de luta, de resistência. 
Essa cenografia é sustentada por uma voz comprometida com a luta pela resistência e pela visibilidade de diversas possibilidades identitárias. Essa voz diz respeito a um "corpo rebelde", que insiste em ocupar, em estar presente, malgrado o efeito de solidão com o qual convive esse enunciador. Esse corpo objetiva sair dos "limbos identitários" criados e mantidos pelos campos médico-científico e midiático. Como exemplar de uma cenografia de manifesto político, o projeto de mudança social do enunciador dar-se-á pela autoafirmação das identidades trans - na conclusão, declara-se que "nunca é alto o preço a se pagar pelo privilégio de pertencer a si mesmo" (GRUPO TRANSCRITAS COLETIVAS, 2017, p. 22) - e pela ocupação promovida por seus corpos.

A parte final do discurso, $\mathrm{A} 1 \$ 4^{\circ}$ e $\mathrm{A} 1 \$ 5^{\circ}$, dedica-se à autoafirmação desse/s corpo/s, construída por um paralelismo estrutural que surge no início de uma sequência de períodos. Principia com a sucessão de "o corpo", "este corpo", "um corpo", "meu corpo", que concernem o corpo do próprio enunciador, até mencionar, ao final, os "corpos" da sua comunidade, uma coletividade esquecida.

O gerenciamento desse ethos discursivo rebelde e combativo faz-se em oposição a outra corporalidade, aquela que é cisgênera, heterossexual e branca. Contemplamos, desse modo, um embate entre o corpo da diferença, "[...] corpo não binário negro que resiste" (GRUPO TRANSCRITAS COLETIVAS, 2017, p. 22), e o corpo reconhecido pela heterossexualidade compulsória. $\mathrm{O}$ posicionamento queer, reivindicado aqui, relaciona a identidade de gênero, parte constituinte dos sujeitos, com outros traços sociais, como classe social e raça/etnia. Sem menosprezar essas interseccionalidades, o enunciador trata dos sujeitos em suas concretudes. Logo, a ênfase na realidade corporal. 
O código linguageiro, aquele negociado pelo enunciador para legitimar seu lugar e sua escolha de cenografia, coloca em uma posição de destaque o corpo trans através da repetição de certa construção, como já assinalado. O "cis-tema”, aglutinação que funde cisgeneridade e sistema e aparece na coletânea desde a sua apresentação, especifica um posicionamento conflitante que vai, ao longo do discurso, ganhando corpo. As escolhas lexicais efetuadas para a constituição desse código linguageiro contribuem para a persuasão do co-enunciador; associa-se aos corpos trans um conjunto de itens que os caracterizam como perseguidos e oprimidos pela cisgeneridade, um sistema que ganha um valor negativo, em oposição: é aquele que oprime e violenta os corpos não conformados.

Outra escolha que se repete ao longo do discurso está apontada no título "Meu corpo e não lugar que ocupo". O "não lugar" referenciado revela uma condição de paratopia espacial, na qual o lugar ocupado pelo enunciador não é seu por completo. Ancorado na sociedade vigente, evoca um lugar fronteiriço, de resistência no e pelo discurso.

Defendemos, porém, que essa representação espacial cumula efeito com a paratopia de identidade. Como gerenciar uma identidade "[...] quando a forma que você se compreende e se identifica não é reconhecida pela sociedade e pelo Estado?" (GRUPO TRANSCRITAS COLETIVAS, 2017, p. 21). Esse questionamento manifesta uma paratopia de identidade do tipo social, segundo a qual se negocia discursivamente uma identidade que, além de não ser legitimada, é violentado pelos espaços sociais correntes. Avancemos para o segundo discurso: 
(A2) Trans.piração ${ }^{32}$

Dia 29 de janeiro,

dia que grita, para além dos 364 , a invisibilidade, a exclusão e o extermínio da população trans/travesti.

(2) Por que será que logo se constroem diagnósticos de doenças mentais para as pessoas antiautoritárias, aquelas que tensionam as regras, que não se submetem às normas?

(3) Pessoas negras escravizadas tentando fugir: drapetomania

Mulheres gritando a misoginia: histeria

Corpos inquietos na escola que silencia: TDAH (Transtorno do déficit de atenção com hiperatividade)

Não aceitação das imposições: TOD (transtorno opositor desafiador)

Pessoas que reivindicam a liberdade de serem como se identificam, como desejam, como se sentem bem: transexualismo/transtorno de identidade de gênero

O que tem produzido as normas?

Aonde têm nos levado as regras?

O que querem [sic] o controle dos corpos?

32 Discurso assinado por Tito Carvalhal. 
(4) Fascismo

Racismo

Machismo

Classismo

Misoginia

LGBTfobia

(5) Pessoas sofrendo a exclusão

A agonia de um viver não permitido

O silenciamento

Preterimento

Apagamento

Extermínio físico e subjetivo

Segregação

Modelo único de ser homem, de ser mulher

Categorização

A disforia chega, irmão

Depressão, transtorno de ansiedade, síndrome do pânico, bipolaridade, suicídio

(6) Problemas de origens multideterminadas (políticas, históricas, culturais, econômicas, sociais) são transformados em individuais

Medicalização

Sua face mais perversa

Patologização 
(7) Pessoas trans não nasceram no corpo errado, mas numa sociedade perversa, que tenta, a todo tempo, nos enquadrar, nos rotular, nos encaixar em papéis previamente definidos, sem levar em consideração as nossas singularidades. Uma vida pensada pra Nós

Sem nós

Mas os corpos escapam

E os desejos transbordam

Transmutação

(GRUPO TRANSCRITAS COLETIVAS, 2017, p. 116-117).

Aqui, são agregadas à cenografia de manifesto político algumas características singulares. $\mathrm{O}$ discurso principia em A2 $\$ 1^{\circ} \mathrm{com}$ o que podemos chamar de um preâmbulo, que discute a invisibilidade e a exclusão dos sujeitos trans e a data 29 de janeiro que marca o Dia da Visibilidade Trans. Essa porção inicial dialoga com A2 $\$ 7^{\circ}$, onde se recupera o tema particular das vivências trans e indica-se um futuro possível no qual as vidas e as singularidades trans serão respeitadas.

Já em $\mathrm{A} 2 \$ 2^{\circ}$, discute-se a patologização em um contexto mais amplo, de todas as "[...] pessoas antiautoritárias, aquelas que tensionam as regras, que não se submetem às normas?" (GRUPO TRANSCRITAS COLETIVAS, 2017, p. 116). A pergunta retórica desse segmento funda a argumentação que será desenvolvida sobre a situação de vulnerabilidade das identidades trans e começa a ser respondida em $\mathrm{A} 2 \$ 3^{\circ}$ por uma série de patologias promovidas pelo campo médico-científico. No primeiro capítulo desta dissertação, discorremos sobre a forma segundo a qual o controle 
médico-científico manteve-se absoluto sobre as identidades que desviaram da matriz cisgênera e heterossexual.

As três perguntas retóricas que surgem na sequência somam-se àquela anterior, criando um efeito argumentativo que sustenta a primeira seção dessa cenografia. Como indicamos na introdução desse grupo de discursos, o objetivo da primeira parte na cenografia de manifesto político é expor uma situação de controle e opressão no contexto sócio-histórico brasileiro, atingindo também uma apresentação negativa daqueles cujo posicionamento mantém-se conservador e normativo.

Outra característica particular desse exemplar verifica-se de $\mathrm{A} 2 \$ 3^{\circ}$ a $\mathrm{A} 2 \$ 6^{\circ}$. A cenografia de manifesto político é, então, tencionada a uma fronteira entre textualidade e aforização. Maingueneau (2010) distingue enunciação textualizante de enunciação aforizante. Naquela, não há uma relação com sujeitos, mas com facetas adequadas àquela cena e que partilham a responsabilidade pelo ato enunciativo. Nesta, diferentemente, "o enunciado pretende exprimir o pensamento de seu locutor, aquém de qualquer jogo de linguagem" (MAINGUENEAU, 2010, p. 14), no qual se centra a enunciação. Para tanto, tende-se a uma homogeneidade enunciativa, não havendo uma dinamicidade entre planos polifônicos, como citações ou paráfrases.

Ao estudar o gênero manifesto artístico, Mussalim (2013) mostra que esse modo de paragrafação e a estruturação sintática dos enunciados, que justapõe sintagmas nominais independentes e períodos simples, abalam o encadeamento dos enunciados e resultam em uma fragmentação que dificulta o desenvolvimento de tópicos discursivos, rompendo com o funcionamento textualizante e instituindo um regime enunciativo que "[...] mina a compacidade da textualização” (MAINGUENEAU, 2010, p. 23). 
Quanto ao código linguageiro concebido, existe uma negociação de efeitos a partir de uma oposição de sintagmas nominais que designam patologias, como em grande parte de $\mathrm{A} 2 \$ 3^{\circ}$ a uma série de outros sintagmas nominais, no segmento seguinte, que indicam situações de exclusão em um macronível. As patologias associadas aos sujeitos que "não se submetem às normas" são substituídas por uma sequência de itens de sufixo "-ismo", como se o enunciador proclamasse as patologias que contaminam a sociedade. Nesse espelhamento, vai construindo-se a defesa de uma análise coletiva das situações de controle e exclusão.

Enquanto tratamos desse embreante, não podemos deixar de relacioná-lo à desterritorialização da língua presente na literatura menor, conforme a caracterizam Gilles Deleuze e Félix Guattari (2017). Na menoridade, o enunciador deve "servir-se da sintaxe para gritar, dar ao grito uma sintaxe" (DELEUZE; GUATTARI, 2017, p. 52). Ponderamos que esse grito é instituído, usufruindo-se da função infralíngua, a qual "[...] está voltada para uma origem que seria uma ambivalente proximidade do corpo, pura emoção: era inocência perdida ou paraíso das infâncias, ora confusão primitiva, caos de que é necessário se desprender" (MAINGUENEAU, 2016a, p. 191). O título "Trans.piração" é indicativo da organização fragmentária e da posição soberana desempenhada pelo enunciador, cuja proposição desenvolvida ao longo do discurso faz-se em uma forma de protesto.

Ao nosso ver, a interferência de uma enunciação com características aforizantes nessa textualização faz emergir um ethos discursivo que está destacado do seu co-enunciador, prescindindo de uma negociação mais direta. Percebemos que ocorre, nesse gerenciamento, um desaparecimento do ethos dito, que legitima e é legitimado por uma relação íntima com uma fonte transcendente, que funda um sujeito independente cujo pensamento, ou tese, advém de um lugar limítrofe. 
Em A2\$7º, observamos a segunda seção dessa cenografia, na qual um projeto que reivindica mudança social e respeito a essas identidades é anunciado. Seu efeito depende de $\mathrm{A} 2 \$ 6^{\circ}$, trecho que discute de que maneira "problemas de origens multideterminadas (políticas, históricas, culturais, econômicas, sociais) são transformados em individuais" (GRUPO TRANSCRITAS COLETIVAS, 2017, p. 117). Essa individualização de uma realidade mais abrangente mina a força da coletividade, que é justamente a proposição final nessa cenografia. Do conflito entre o posicionamento queer do enunciador e o posicionamento conservador e opressivo do outro descrito, dimana o projeto de uma "Uma vida pensada pra Nós/ Sem nós” (GRUPO TRANSCRITAS COLETIVAS, 2017, p. 117).

À medida que se entrevê um lugar (topografia) de crueldade, de perversidade contra as identidades trans, vai revelando-se um tempo (cronografia) de reivindicação e de mudança, semelhante ao que se desenrola em A1. Conclui-se o discurso convocando um transbordamento, uma "transmutação" dos corpos trans. O oferecimento dessa linha de fuga expressa uma reversão da lógica que, em primeiro lugar, patologiza a transgeneridade e, em seguida, liga-a em uma relação de origem e causa a transtornos mentais - "depressão, transtorno de ansiedade, síndrome do pânico, bipolaridade, suicídio" (GRUPOS TRANSCRITAS COLETIVAS, 2017, p. 117) - que podem levar ao suicídio. No projeto defendido pelo enunciador, somente um entendimento coletivo das situações de exclusão pode reverter a vulnerabilidade com a qual convivem as experiências trans. Concluímos esta seção com o terceiro discurso selecionado: 
(A3) Um pouco sobre interseccionalidade e invisibilidade trans ${ }^{33}$

(1) Ser uma mulher negra, transexual e pesquisadora me traz uma perspectiva social que me ajuda a compreender o modo como diversas estruturas de opressão da nossa cultura se interagem e agem sobre meu corpo, $e$, consequentemente, quais são minhas estratégias de resistência diante das violências que enfrento. Assim, é resgatando minha história e meus diversos processos de transformação que vou tecendo um melhor entendimento sobre quem eu sou, e, também, sobre as atuações do racismo, da transfobia e do machismo na minha vida.

(2) Constituir minha mulheridade e feminilidade foi uma trajetória regada de processos conscientes e inconscientes. Na nossa cultura, parece que falar de transição de gênero requer que sempre haja um estopim, um início, mas, na verdade, pode acontecer sem que a gente tenha estipulado esse momento. Desde pequena, eu sei que já me reconhecia como uma pessoa feminina; a feminilidade já estava ali estabelecendo minha identidade. E, só com o passar dos anos que eu comecei a me identificar enquanto Mulher. A partir de uma certa idade, então, resolvi adequar meu corpo, e comecei a construir minha imagem de mulher trans. Todo esse caminho que fiz foi muito fascinante, mas, também, de muita dor. Foi bom, porque eu pude me ver um pouco mais parecida com a idealização de corpo que criei para mim; pude trocar experiências com outras mulheres trans; e senti que tinha me tornado uma pessoa mais feliz, mais alegre. Até

33 Discurso assinado por Jaqueline Gomes de Jesus. 
da minha família eu me aproximei mais! Minhas tias sempre me acompanharam desde a infância, elas sabiam como eu era, já me conheciam, e não foi nenhuma surpresa para elas. Porém, como disse, há o lado triste e doloroso de ser esse tipo de mulher em uma sociedade transfóbica.

(3) As violências que são direcionadas para mim estão relacionadas com as especificidades que possuo, enquanto a mulher que sou dentro do universo da "mulheridade". Todas as mulheres carregam semelhanças entre si, mas, principalmente, diferenças. Pensando especificamente na dimensão da transgeneridade, há algumas questões políticas e sociais que dizem respeito só às $\mathrm{mu}$ lheres que são como eu, como, por exemplo, certos cuidados com o corpo, determinadas relações interpessoais, adversidades no quesito da saúde e segurança pública, entre outras coisas. E, quando se analisa a transgeneridade junto com raça/etnia, pode-se perceber outras produções de violência. Eu costumo a pensar que as violências direcionadas às mulheres trans negras não são somadas, mas, sim, multiplicadas. Nós sofremos muito mais opressões que as mulheres trans não negras, principalmente, as brancas. Tanto a transfobia, quanto o racismo e o machismo vão nos atingir de forma muito mais perversa e violenta. Como exemplo disso, posso citar a própria construção de nossa mulheridade negra. É sempre imposto para nós, na constituição de nossos corpos, os moldes de feminilidade da mulher branca. E, isso é bastante violento!

(4) Além dessas violações que recaem sobre nós fisica- 
mente e psicologicamente, é preciso afirmar que há, também, um epistemicídio de nossos conhecimentos, isto é, uma violência que nega ou não reconhece o que construímos intelectualmente sobre nós mesmas, enquanto pessoas negras e trans. É muito comum minha produção intelectual e a das/os minhas/meus colegas serem invisibilizadas na academia; é comum as pessoas não se interessarem, não lerem; ou quando leem, repetem nossos pensamentos e contribuições, mas nem ao menos citam nossos nomes. Minhas investigações não são só sobre a temática das identidades de gênero, mas, também, sobre movimentos sociais e psicologias das massas, e tudo isso é invisibilizado. A academia tem uma responsabilidade muito grande na perpetuação do racismo e da transfobia.

(5) Nós, pessoas trans, em geral, temos muito o que falar para as pessoas cis. Já temos toda uma oralitura - uma literatura oral - sobre nós mesmas e sobre dissidências corporais, e a linguagem escrita é mais um campo de divulgação e produção que deve ser disputado por nós. E, nos últimos tempos, nós temos criado muita coisa. Eu vejo muitas/os jovens trans no meio virtual que escrevem, em redes sociais e em blogs, sobre as nossas realidades e especificidades, e isso é muito rico, é resistência! Algumas/alguns de nós têm essa escrita mais acadêmica, voltada para a pesquisa, para a investigação, e eu espero que esse número cresça. Se a transfobia é uma estrutura de opressão que impede o acesso de nossa população à permanência no sistema educacional, ao trabalho, e à renda, ela também afeta nossa produção intelectual. 
(6) Diante disso, é possível afirmar que a transfobia, no Brasil, é um novo paradigma para a luta pelos Direitos Humanos. Pois, o nosso país é o que mais mata nossa população no mundo todo; as travestis negras, por exemplo, são alvos constantes de uma das violências de gênero que é o transfeminicídio. Por isso, nossos direitos civis só poderão ser assegurados se, antes de tudo, formos reconhecidas/os como humanas/os, seres possíveis e existentes.

(GRUPO TRANSCRITAS COLETIVAS, 2017, p. 131-133).

Em A3, a cenografia de manifesto político apoia-se em trechos de narração que rememoram experiências do enunciador. Essa escolha discursiva inaugura e auxilia na sustentação da argumentação típica dessa cenografia. Logo em $\mathrm{A} 3 \$ 1^{\circ}$, justifica-se de que forma o discurso progredirá: “[...] é resgatando minha história e meus diversos processos de transformação que vou tecendo um melhor entendimento sobre quem eu sou, e, também, sobre as atuações do racismo, da transfobia e do machismo na minha vida" (GRUPO TRANSCRITAS COLETIVAS, 2017, p. 131). Em A3\$2, opera-se essa narração de cunho pessoal que coloca o enunciador em uma posição autorizada de enunciação.

Tanto o título "Um pouco sobre interseccionalidade e invisibilidade trans" como esses dois primeiros parágrafos sinalizam e desenvolvem uma voz distinta das analisadas até este momento. Aparece aqui um ethos discursivo que, em uma dimensão ideológica, nos termos de Maingueneau (2016b), aproxima-se dos ethé negociados em A1 e A2, mas, em uma dimensão experiencial, mostra-se reflexivo e judicioso. 
Ao final de $\mathrm{A} 3 \$ 2^{\circ}$, temos “porém, como disse, há o lado triste e doloroso de ser esse tipo de mulher em uma sociedade transfóbica" (GRUPO TRANSCRITAS COLETIVAS, 2017, p. 131-132), período que introduz uma cena mais coletiva e negativa da situação com a qual convivem os sujeitos trans. Discutem-se as violências a que estão submetidos, a maneira pela qual a transfobia alia-se a outras formas de discriminação, como o machismo e o racismo, e apagamento da produção discursiva desses sujeitos. $\mathrm{O}$ posicionamento queer traz para o discurso esse entrecruzamento de experiências e de lugares. Essa cena estende-se até $\mathrm{A} 3 \$ 4^{\circ}$.

Observado no nível do código linguageiro, há, nesse segmento, um paralelismo estrutural que expressa uma necessidade de ação que culminará no fecho do discurso em A $3 \$ 5^{\circ}$ e A2\$6 . Nos enunciados "é preciso afirmar que há, também, um epistemicídio [...]", "é muito comum [...]" e "é comum as pessoas não se interessarem [...]” (GRUPO TRANSCRITAS COLETIVAS, 2017, p. 132), o enunciador reforça um cenário que necessita da participação do co-enunciador para que uma mudança social se efetive.

Ainda no nível do código linguageiro, se compararmos este discurso ao anterior, A2, verificamos o predomínio da função supralíngua, que, ao contrário da infralíngua, "[...] acena com a perfeição luminosa de uma representação idealmente transparente ao pensamento. Um e outra, por caminhos opostos, sonham com um sentido que seria imediato, que se daria sem qualquer reserva" (MAINGUENEAU, 2016a, p. 191). Esse uso legitima e é legitimado pela voz arrazoada que se impõe nessa cenografia para defender o combate à transfobia e o seu direito a uma existência social plena.

Conforme preconiza essa configuração cenográfica, constrói-se em $\mathrm{A} 3 \$ 5^{\circ}$ uma apresentação apreciativa da comunidade trans: "nós, pessoas trans, em geral, temos muito o que falar para as pes- 
soas cis" (GRUPO TRANSCRITAS COLETIVAS, 2017, p. 132). Contemplamos que a cenografia se sustenta em um tempo (cronografia) de aprendizado, de reflexão, que se dá em lugar (topografia) do diálogo, de troca de experiências que possam propiciar uma mudança social.

A começar em $\mathrm{A} 3 \$ 5^{\circ}$, o enunciador explicita seu projeto, que, em consonância com seu posicionamento, aprecia a convivência entre diferentes. Como afirmado antes, em A3\$3。: "todas as mulheres carregam semelhanças entre si, mas, principalmente, diferenças" (GRUPO TRANSCRITAS COLETIVAS, 2017, p. 132). Essa proposição de transformação da situação atual das/os trans passa de uma perspectiva do "eu" para uma mais coletiva, do "nós". Essa alteração de um enunciador que fala sobre si para propor uma pauta social, em um contexto coletivo, de combate à transfobia e a outras formas de opressão justifica as particularidades discursivas conciliadas à configuração cenográfica.

No último parágrafo, $\mathrm{A} 3 \$ 6^{\circ}$, a fim de certificar o propósito coletivo e a urgência da transformação social, conclui-se com a informação de que o Brasil é o país que mais mata a população trans no mundo. Ao fim, a visão subjetiva cede espaço a uma contextualização do cenário brasileiro que não garante direitos civis a essa população. A menção direta à luta por direitos civis expõe que, na situação atual, esses sujeitos não são respeitados de forma plena e a eles é reservado um pertencimento social vacilante.

\section{Considerações finais}

Neste trabalho, examinamos a produção discursivo-literária de sujeitos transgêneros desenvolvida em uma cenografia de ma- 
nifesto político. Os resultados da análise atestam que, além de se constituir de forma paratópica nas três dimensões analisadas, essa produção discursivo-literária busca criar um lugar social para esses sujeitos por meio da resistência à matriz cisgênera.

Por estarem alicerçados em um posicionamento queer, segundo o qual o gênero é performado discursivamente e, por isso, pode apresentar-se em inúmeras expressões, esses discursos gerem em suas cenas um dissenso com um posicionamento conservador e biologizante do gênero. $O$ conflito entre esses dois posicionamentos insere, pois, uma caracterização pejorativa para os associados a um posicionamento heterocisconformista e uma apreciativa para os vinculados ao posicionamento queer, no qual todos os enunciadores dos discursos analisados se localizam.

Apontamos ainda que há, nos termos de Deleuze e Guattari (2017), um agenciamento coletivo da enunciação, no e por meio do qual cada característica individual citada é índice para uma história maior, coletiva. Nesses discursos, um sujeito, que representa um grupo, coloca-se em uma posição de confronto em relação ao pertencimento social reservado às identidades do seu grupo.

Mimetizando o manifesto político, a cenografia desses discursos aborda as identidades trans como índices de exclusão social: aquelas/es que não se conformam à cisgeneridade não exercem uma cidadania plena. Mesmo que se passe em alguns pontos por outras representações da paratopia, como a corporal, o efeito final instituído nessa sobreposição de representações indica um pertencimento social contingente.

Os projetos de mudança admitidos pelos enunciadores envolvem, em última instância, o autopertencimento dos sujeitos trans pertencer a si mesmo, isto é, uma posse de suas próprias histórias 
e a afirmação de suas diferenças. Diante desse cenário, haja vista sua dimensão experiencial, emerge um ethos discursivo coletivo do descontentamento social, portanto.

Quando entendemos que "a política de identidade não é uma luta entre sujeitos naturais; é uma luta em favor da própria expressão da identidade" (WOODWARD, 2014, p. 37), podemos alcançar a produtividade da noção de paratopia de gênero para o campo de pesquisa do discurso literário na $\mathrm{AD}$. A luta travada pela liberdade de expressão da identidade de gênero viabiliza produções discursivo-literárias bastante heterogêneas que requerem investigações comprometidas.

Em conclusão, julgamos que a análise do corpus selecionado torna possível uma expansão do estudo sobre a representação da paratopia de gênero. Esse movimento ajudaria a explicitar o discurso literário em uma dimensão pedagógica, configurando-se como uma prática discursiva que indaga os comportamentos e/ou papéis de gênero estabilizados para determinada identidade. Além disso, este tipo de discurso auxilia na chancela ou na desestabilização do imaginário de gênero corrente, ou seja, as identidades discursivas podem ser agenciadas como embreantes paratópicos resistentes à estratificação das identidades de gênero baseada em argumentos que a fazem parecer natural, imutável.

\section{Referências}

BUTLER, Judith. Como os corpos se tornam matéria: entrevista com Judith Butler. Trad. Susana Bornéo Funck. Estudos feministas, Florianópolis, v. 10, n. 1, p. 155-167, 2002. Entrevista concedida a Baukje Prins e Irene Costera Meijer. Disponível em: <http://www.scielo.br/pdf/ref/v10n1/11634. 
pdf $>$. Acesso em: 05 jun. 2019.

Relatar a si mesmo: crítica da violência ética. Trad. Rogério Bettoni. Belo Horizonte: Autêntica, 2015.

. Problemas de gênero: feminismo e subversão da identidade. Trad. Renato Aguiar. 11. ed. Rio de Janeiro: Civilização Brasileira, 2016.

COSSETTI, Rafael. Diferença e coletividade: a produção discursivo-literária de sujeitos transgêneros. Orientador: Jarbas Vargas Nascimento. 2019. 145 f. Dissertação (Mestrado em Estudos Linguísticos) - Programa de Pós-Graduação em Linguística, Universidade Federal do Espírito Santo, Vitória, 2019.

DELEUZE, Gilles; GUATTARI, Félix. Kafka: por uma literatura menor. Trad. Cíntia Vieira da Silva. 1. ed. 3. reimp. Belo Horizonte: Autêntica, 2017.

GRUPO TRANSCRITAS COLETIVAS. Nós, trans: escrevivências de resistência. São Paulo: LiteraTRANS, 2017. E-book.

JESUS, Jaqueline Gomes de. Orientações sobre identidade de gênero: conceitos e termos. Guia técnico sobre pessoas transexuais, travestis e demais transgêneros, para formadores de opinião. 2. ed. rev. ampl. Brasília: Ser-Tão/UFG, 2012. Disponível em: <http://www.sertao.ufg.br/up/16/o/ORIENTA\%C3\%87\%C3\%95ES_POPULA\%C 3\%87\%C3\%83O_ TRANS.pdf?1334065989>. Acesso em: 22 abr. 2018.

MAINGUENEAU, Dominique. O contexto da obra literária: enunciação, escritor, sociedade. Trad. Marina Appenzeller. São Paulo: Martins Fontes, 1995.

. Novas tendências em análise do discurso. Trad. Freda Indursky. 3. ed. Campinas: Pontes, 1997.

Gênese dos discursos. Trad. Sírio Possenti. São Paulo: Parábola, 2008.

Doze conceitos em análise do discurso. Org. Sírio Possenti e Maria Cecília Perez de Souza-e-Silva. Trad. Adail 
Sobral et al. São Paulo: Parábola, 2010.

. Discurso literário. Trad. Adail Sobral. 2. ed. São Paulo: Contexto, 2016a.

. Retorno crítico sobre o ethos. Trad. Paula Camila Mesti. In: BARONAS, Roberto Leiser; MESTI, Paula Camila; CARREON, Renata de Oliveira (org.). Análise do discurso: entorno da problemática do ethos, do político e de discursos constituintes. Campinas: Pontes, 2016b.

MUSSALIM, Fernanda. A enunciação aforizante: o caso do gênero manifesto. Delta, São Paulo, v. 29, especial, p. 467484, 2013.

PELÚCIO, Larissa. Traduções e torções ou o que se quer dizer quando dizemos queer no Brasil? Periódicus, Salvador, v. 1, n. 1, p. 68-91, maio/out. 2014.

WOODWARD, Kathryn. Identidade e diferença: uma introdução teórica e conceitual. Trad. Tomaz Tadeu da Silva. In: SILVA, Tomaz Tadeu da (org.). Identidade e diferença: a perspectiva dos estudos culturais. 15. ed. Petrópolis, RJ: Vozes, 2014. p. 7-72. 